James K. Hammitt

\title{
Extrapolating the Value Per Statistical Life Between Populations: Theoretical Implications
}

\begin{abstract}
Extrapolation of estimates of the value per statistical life (VSL) from high- to low- or middle-income populations requires attention to the possible effects of differences in income, current mortality risk, health, life expectancy, and many other factors. The standard theoretical model of VSL implies that VSL increases with income and decreases with current mortality risk. The effect of mortality risk is likely to be negligible while the effect of income is large and poorly quantified. Effects of differences in life expectancy and health are theoretically ambiguous. Effects of other factors, including differences in health care, formal and informal support networks, and cultural or religious factors that affect preferences for spending on oneself or others may be important but are unknown. Practical issues include choice of the most appropriate measure of income and possible differences in the patterns of age dependence between populations.
\end{abstract}

Keywords: benefit transfer; income elasticity; value per statistical life.

JEL classifications: D6; I1; Q51.

\section{Introduction}

The paucity of studies providing high-quality estimates of the value per statistical life (VSL) in lower-income and middle-income countries (LMICs) forces analysts conducting benefit-cost analyses for those countries to extrapolate from estimates for the United States or other high-income countries (a process known as "benefit transfer"). It is common to adjust for differences in income, though the appropriate magnitude of the adjustment (quantified as the income elasticity of VSL) is unknown (Viscusi \& Masterman, 2017). Moreover, adjusting only for

\footnotetext{
James K. Hammitt: Harvard University (Center for Risk Analysis), 718 Huntington Ave., Boston, MA 02115, USA and
}

Toulouse School of Economics, Université Toulouse Capitole, 21, allée de Brienne, 31000 Toulouse, France, e-mail: jkh@ @arvard.edu, Phone: +1 617432 4343, Fax: +1 617432 0190. 
income differences leaves much of the variation between estimates in different populations unexplained (Hoffmann, Krupnick \& Qin, 2017). In principle, analysts should adjust not only for differences in income but for all the factors that differ between the source and target population and significantly affect VSL. Without plentiful high-quality estimates of VSL in LMICs, it is difficult to know which of the many differences between source and target populations (including income, life expectancy, health, access to medical care and to formal or informal support networks) significantly affect VSL or the magnitudes of their effects.

I present the standard economic model of VSL and investigate its implications for the effects of different factors on VSL. The model implies that lower wealth (or income) should reduce VSL and that the wealth elasticity should be at least as large as the Arrow-Pratt measure of relative risk aversion with respect to wealth. Measuring and comparing real wealth or income is complex and the best practical measure is uncertain, as populations differ in the shares of income and consumption flowing through markets and the shares provided by government or communities. Higher age-specific mortality risk should increase VSL, but the magnitude of this effect should be small in most cases. In contrast, the effects of differences in health and age-specific life expectancy are ambiguous. Other factors that influence individuals' preferences for spending resources on their own survival or to benefit family or community members could be important, but the directions and magnitudes of these effects are unknown.

\section{The standard model}

An individual's VSL may be defined as her marginal rate of substitution between wealth, $w$, and probability of surviving the current period, $s$. The standard model assumes the individual wishes to maximize her expected state-dependent utility,

$$
U=s u_{a}(w)+(1-s) u_{d}(w),
$$

where $u_{a}(w)$ and $u_{d}(w)$ represent her state-dependent utility of wealth conditional on surviving and not surviving the current period, respectively (Drèze, 1962; JonesLee, 1974; Weinstein, Shepard \& Pliskin, 1980). The utility function for wealth conditional on failing to survive the period represents the individual's preferences with respect to her bequest (and for consumption during any part of the period she survives). It is conventional to assume that:

$$
\begin{gathered}
u_{a}(w)>u_{d}(w), \\
u_{a}^{\prime}(w)>u_{d}^{\prime}(w) \geqslant 0, \quad \text { and }
\end{gathered}
$$




$$
u_{a}^{\prime \prime}(w) \leqslant 0 ; u_{d}^{\prime \prime}(w) \leqslant 0
$$

In words, at all relevant levels of wealth: survival is preferred to death $(2 a)$; the marginal utility of wealth is nonnegative and strictly larger given survival than death equation $(2 b){ }^{1}$ and the individual is weakly risk averse with respect to wealth, given survival or death.

VSL is obtained by totally differentiating equation (1) with respect to wealth and survival probability to yield

$$
\mathrm{VSL}=-\frac{d w}{d s}=\frac{u_{a}(w)-u_{d}(w)}{s u_{a}^{\prime}(w)+(1-s) u_{d}^{\prime}(w)}=\frac{\Delta u(w)}{E u^{\prime}(w)}
$$

VSL is the ratio of the utility gain from surviving the current period (the numerator in equation (3)) to the expected opportunity cost of spending (the denominator). From assumptions $(2 a)$ and $(2 b)$, both numerator and denominator are strictly positive, and hence VSL is positive.

The effect of wealth on VSL can be seen by inspection (and verified by differentiation). An increase in wealth strictly increases the numerator (by assumption $(2 b)$ ) and weakly decreases the denominator (by assumption $(2 c)$ ), yielding an increase in the ratio. The magnitude of the effect depends on the proportional difference between the marginal utility of wealth given survival and as a bequest (i.e., the ratio $\left.u_{a}^{\prime}(w) / u_{d}^{\prime}(w)\right)$ and the rate at which the expected marginal utility of spending diminishes with wealth, which depends on the degrees of risk aversion toward wealth conditional on survival and death.

A theoretical lower bound on the magnitude of the effect of wealth on VSL comes from observing that the income elasticity of WTP $(\eta)$ is strictly larger than

1 Individuals can reallocate wealth between the states of survival and death through use of life insurance, annuities, and similar contracts. If actuarially fair life insurance and annuities are available, it is easy to show that the optimal policy transfers wealth from the bequest to the state of survival. Let $x$ be the insurance payment in the event of death. Then actuarially fair insurance pays $-[(1-s) / s] x$ in the event of survival. Substitution into equation (1) yields $U=s u_{a}(w-[1-s / s] x)+(1-s) u_{d}(w+x)$. Differentiation with respect to $x$ yields the first-order condition for optimality (that the marginal utility of wealth is equal in the states of survival and death), $u_{a}^{\prime}(w-[(1-s) / s] x)=u_{d}^{\prime}(w+x)$. From assumptions $(2 b)$ and $(2 c)$, satisfaction of this condition (if it is possible) requires $x<0$, i.e., a transfer from the bequest to the event of survival. If the condition cannot be satisfied (e.g., if $\left.u_{a}^{\prime}([1+(1-s) / s] w)>u_{d}^{\prime}(0)\right)$, optimal insurance is the corner solution in which as much wealth as possible is transferred from the bequest to the event of survival. If (as is generally true) insurance is actuarially unfair, the optimal transfer is smaller and the marginal utility of wealth given survival strictly exceeds the marginal utility of wealth as a bequest (where the levels of wealth differ because of the transfer). 
the degree of relative risk aversion with respect to wealth. To see this, let

$$
\begin{aligned}
\eta & =\frac{\partial \mathrm{VSL} / \mathrm{VSL}}{\partial w / w}=\frac{\partial \mathrm{VSL}}{\partial w} \cdot \frac{w}{\mathrm{VSL}} \\
& =w \frac{u_{a}^{\prime}(w)-u_{d}^{\prime}(w)}{u_{a}(w)-u_{d}(w)}-w \frac{s u_{a}^{\prime \prime}(w)+(1-s) u_{d}^{\prime \prime}(w)}{s u_{a}^{\prime}(w)+(1-s) u_{d}^{\prime}(w)}
\end{aligned}
$$

The second term in expression ( $4 b$ ) is a generalization of the Arrow-Pratt coefficient of relative risk aversion with respect to wealth (Pratt, 1964) that accounts for the state-dependent utility equation (1) and is conditional on survival probability $s$. Under assumptions $(2 b)$ and $(2 c)$, this term is greater than or equal to zero. The first term is strictly greater than zero (under assumptions $(2 a)$ and $(2 b)$ ); hence the income elasticity of VSL is greater than the degree of relative risk aversion with respect to wealth. This result was obtained for special cases by Eeckhoudt and Hammitt (2001) and by Kaplow (2005). Kaplow reports typical estimates of the coefficient of relative risk aversion from the financial literature equal to two or larger; Eeckhoudt and Hammitt report that it is reasonable to assume values between about 0.5 and 2.5. Note that equation $((4 a),(4 b))$ is a local result; both the income elasticity of VSL and the coefficient of relative risk aversion may vary with wealth, but at each wealth level the former must exceed the later (which implies the average income elasticity over any range must exceed the average coefficient of relative risk aversion over that range).

Conventional estimates of VSL exceed individual wealth, which seems reasonable. ${ }^{2}$ Intuitively, one can divide the utility gain from survival (the numerator of equation (3)) into two components, the present value of consumption (compared with leaving wealth as a bequest) and the incremental wellbeing of living beyond that provided by consumption. If the utility from wealth that is consumed is much greater than from wealth used as a bequest and if the increment to wellbeing beyond that from consumption is positive, then VSL exceeds consumption. Hammitt and Robinson (2011) use the assumption that VSL exceeds the present value of income or consumption to define lower bounds when extrapolating VSL to lower-income populations.

2 Studies of VSL rarely report wealth. However, conventional estimates of VSL are much larger than current income, future income, and wealth for the average individual. For example, Viscusi (2004) estimates US VSL as about \$5 million using data on workers (average age about 40 years). Grosse (2003) provides a contemporaneous estimate of the present value of future income and household production ( $\$ 1.1$ million), a factor of five smaller, and US per capita GNI was about $\$ 44,000$ (2005, World Bank), a factor of 100 smaller. The ratio of wealth to income varies over the lifecycle, but was 4.1 (using means) and 1.4 (using medians) for American households headed by a 35- to 44-year-old (calculations using data from Bucks, Kennickell \& Moore, 2006), much less than the ratio of VSL to income. 
Reasonable though it may seem, the result that VSL exceeds wealth does not follow from the standard model. Assume (without loss of generality) that $u_{a}(w)>0$ for all $w$ such that living is preferred to death and that

$$
u_{d}(w)=\alpha u_{a}(w)-\delta
$$

where $0 \leqslant \alpha<1$ and $\delta \geqslant 0$, which satisfies assumptions ( $2 a)$ and ( $2 b)$. Substituting assumption (5) into equation (3) yields

$$
\mathrm{VSL}=\frac{(1-\alpha) u_{a}(w)+\delta}{[s+(1-s) \alpha] u_{a}^{\prime}(w)}
$$

When $\alpha=0$, VSL $=\left[u_{a}(w)+\delta\right] / s u_{a}^{\prime}(w) \geqslant w$, where the inequality follows because assumptions (2b) and (2c) imply $u_{a}(w) / w \geqslant u_{a}^{\prime}(w)$, i.e., the average incremental utility of wealth exceeds the marginal utility. In this case, VSL exceeds wealth. In contrast, when $\alpha>0$, VSL can be smaller than wealth. To illustrate, in the limit as $\alpha$ approaches one VSL approaches $\delta / u_{a}^{\prime}(w)$, which can be arbitrarily small as $\delta$ approaches zero. Unsurprisingly, if the difference in utility between survival and death is small, then VSL can be small. ${ }^{3}$

The effect of current survival probability on VSL is also evident from equation (3). An increase in $s$ puts more weight on the first term and less weight on the second term of the denominator and hence increases the denominator (by assumption $(2 b)$ ). It has no effect on the numerator; hence VSL decreases. This effect is described as the "dead-anyway effect" (Pratt \& Zeckhauser, 1996): a decrease in survival probability decreases the expected opportunity cost of spending and hence increases VSL. ${ }^{4}$ The magnitude of this effect is constrained by the ratio of survival probabilities and so will be small when survival probabilities are close to one. Note that the magnitude of the dead-anyway effect is largest when $u_{d}^{\prime}(w)=0$, ceteris paribus. In this case, a decrease in $s$ from $s_{0}$ to $s_{0}-\varepsilon$ increases VSL by the factor $s_{0} /\left(s_{0}-\varepsilon\right)<1 /\left(s_{0}-\varepsilon\right)$. In words, the proportional effect of a difference in period-specific survival probability between a source and target population cannot exceed the ratio of the larger to the smaller survival probability, which is less than the reciprocal of the smaller survival probability.

The state-dependent utility functions $u_{a}(w)$ and $u_{d}(w)$ depend on the individual's anticipation of future conditions. The utility function given survival almost certainly depends on the individual's expectations about her longevity, future health,

3 Bergstrom (1982) presents an early and comprehensive evaluation of the question "When is a man's life worth more than his human capital?".

4 When perfect insurance is available, the marginal utility of (post-transfer) wealth conditional on survival and on death are equal and so an increase in $s$ has no effect on the denominator. In this case, VSL increases because the price of insurance rises and hence the insured wealth levels in the two states decrease (Breyer \& Felder, 2005). 
income, family circumstances, and other factors if she survives the period. Factors that increase this utility (such as greater life expectancy, better anticipated health, or more grandchildren) increase the numerator of equation (3). But they may also increase the marginal utility of wealth given survival $u_{a}^{\prime}(w)$, increase the denominator, and (if the effect is large enough) decrease VSL. To illustrate, consider an individual supporting herself from a fixed wealth with no prospect of future income. A longer life expectancy requires her to husband her resources more carefully, increasing the opportunity cost of spending; this effect could be mitigated by strong income or other support, whether through formal government programs or informal family or community networks. Alternatively, strong support networks could increase the utility of the bequest as the individual would know her dependents would be well cared for after her death, hence reducing her VSL. ${ }^{5}$ Similarly, better future health can expand the set of possibilities for spending wealth to increase utility (and worse future health can contract it). There is some empirical support for the hypothesis that the marginal utility of wealth is increasing in health (Viscusi \& Evans, 1990; Sloan, Viscusi, Chesson, Conover \& Whetten-Goldstein, 1998; Finkelstein, Luttmer \& Notowidigdo, 2013). Future health and longevity can affect future income (by increasing earnings capacity and decreasing medical-care expenses), which should increase VSL. In sum, the effects of factors such as life expectancy and future health on VSL are ambiguous.

\section{Extrapolating VSL from higher- to lower-income populations}

Compared with higher-income populations that are the source of most high-quality estimates of VSL, populations in LMICs tend to have lower income and wealth, higher age-specific mortality and shorter life expectancy, and poorer health. Formal systems of income and health support also tend to be weaker. Depending on the specific populations, there may be important differences in household size, family or informal support networks, and in religious or cultural factors that affect preferences for spending resources on one's own survival, on other family members, or on others. Each of these factors may affect the state-dependent utility functions and hence the relationship between VSL in the source and target population.

5 For example, parents may believe it is more important to stay alive when their children are young and need care than when the children are older. With stronger family or other networks to support their children, this differential might be smaller. 
The standard one-period model suggests VSL may change over the lifecycle: it can depend on multiple factors that vary with age, including life expectancy, health, and wealth. Models that include multiple periods typically find that VSL increases then decreases with age, although VSL can decline monotonically with age when individuals can borrow against future income (Shepard \& Zeckhauser, 1984; Rosen, 1988; Ng, 1992). Empirical studies tend to find a similar pattern, though the literature provides no consensus about the age at which VSL peaks or how much it changes over the lifecycle (Krupnick, 2007; Aldy \& Viscusi, 2008).

The expectation that VSL varies with age implies that extrapolating from a source to a target population requires accounting for age effects. In principle, the age dependence of VSL could differ between the source and target populations. Even if the pattern is similar, the question remains how to extrapolate between populations having different life expectancies, i.e., whether the time path of VSL is similar when described as a function of age, of current life expectancy, of the fraction of initial life expectancy already lived, or as some other measure of stage of the lifecycle. For example, Aldy and Viscusi (2008) estimate that VSL among US nonagricultural workers peaks near age 45 (cohort-adjusted estimates). US life expectancy is about 77 years at birth and 36 years at age 45. In Ethiopia, life expectancy is 63 years at birth and 30 years at age $45 .^{6}$ In extrapolating from the United States to Ethiopia, should one assume that VSL in Ethiopia peaks at the same age (45), the age with the same life expectancy (37), the same fraction of life expectancy at birth (by coincidence, also 37), or at some other age? Similarly, there is evidence that in the United States and other high-income countries VSL for children (defined as parents' rate of substitution between their wealth and their child's survival probability) exceeds adults' VSL (Gerking \& Dickie, 2013). The relationship between VSL for children and adults may well differ between populations.

Adjustment for differences in wealth also requires attending to the appropriate definition of wealth or income. The benefits of surviving beyond the current period and the opportunity cost of spending depend on consumption, which depends on wealth and income. In principle, some measure of permanent consumption or a combination of current wealth and anticipated future income seems relevant, as one can borrow against future consumption to some extent. Statistics on income are more accessible than on wealth or consumption. Income incorporates many components, including money income, goods and services provided by government, and goods and services produced and consumed outside the market (such as food produced by farmers for their own consumption). Differences between populations in the shares of these components raise questions about which available

6 Life expectancies from the World Health Organization (Global Health Observatory) http://apps.who. int/gho/data/node.main.LIFECOUNTRY?lang=en, accessed 6 June 2017. 
Table 1 Selected estimates of income, consumption, and components.

\begin{tabular}{lrrr}
\hline & United States & Vietnam & Ethiopia \\
\hline a. GDP per capita & 41,674 & 2142 & 591 \\
b. Actual consumption & 31,995 & 1309 & 477 \\
b/a & $77 \%$ & $61 \%$ & $81 \%$ \\
c. Individual consumption by households & 29,322 & 990 & 389 \\
$\quad$ c/(c+d) & $92 \%$ & $63 \%$ & $90 \%$ \\
d. Individual consumption by government & 2673 & 575 & 43 \\
d/(c+d) & $8 \%$ & $37 \%$ & $10 \%$ \\
e. Collective consumption by government & 3956 & 367 & 126 \\
e/a & $9 \%$ & $17 \%$ & $21 \%$ \\
f. Capital formation & 8006 & 634 & 73 \\
f/a & $19 \%$ & $30 \%$ & $12 \%$ \\
\hline
\end{tabular}

Source: World Bank (2008, Table 6). Values are in 2005 international dollars.

measure of income is most appropriate for extrapolation. Moreover, the real value of consumption depends on the prices of consumption goods; price levels and price ratios between goods differ substantially across countries. Purchasing-power-parity adjustment attempts to account for these differences, but the best adjustment is uncertain because patterns of consumption differ between populations because of differences in price ratios and possibly differences in utility functions.

To illustrate, consider estimates of income for three countries reported in international (purchasing-power-parity adjusted) dollars in Table 1. GDP per capita, a measure of the value of goods and services exchanged in markets supplemented by estimates of some nonmarket components (such as the imputed rental value of owner-occupied housing) is about \$42,000 in the US, \$2,100 in Vietnam, and \$600 in Ethiopia. Actual consumption is less than GDP per capita in all three countries by factors that differ significantly, ranging from almost one fifth in Ethiopia to almost two fifths in Vietnam.

The extent to which consumption is provided through government or purchased by households also differs, with government shares of household consumption of one tenth or less in the United States and Ethiopia but larger than one third in Vietnam. The components of GDP allocated to collective consumption by government (e.g., defense, justice, general administration, environmental protection) range from less than one tenth in the United States to more than one fifth in Ethiopia. The fraction of GDP per capita invested in capital formation also differs, ranging from $12 \%$ in Ethiopia to $30 \%$ in Vietnam. Investment in capital formation may alter the time 
path of consumption (increasing future and decreasing current consumption); its effect on temporally averaged "permanent" consumption is uncertain.

What measure of relative income is most representative of differences between populations in the benefit of survival and opportunity cost of spending? GDP per capita is the most comprehensive measure included in these data, though it is incomplete as it excludes some nonmarket components of income and consumption that may differ between populations; it may also exclude the value of consumption exchanged through informal markets. Individual consumption by households is perhaps the narrowest measure and may approximate money income. In allocating household resources to reduce mortality risk, do households take a more or less comprehensive view of their consumption and resources? Using GDP per capita, US income is about 20 times larger than in Vietnam and 70 times larger than in Ethiopia. Using individual consumption by households, the corresponding ratios are 30 for Vietnam and 75 for Ethiopia (about $50 \%$ and $5 \%$ larger, respectively). The most appropriate choice between these (or other) alternative measures of wealth or income is uncertain and can have a significant effect on the extrapolated VSL.

\section{Conclusion}

The standard model defines VSL as the marginal rate of substitution between wealth and the probability of surviving the current period, often interpreted as the current year. In this model, VSL increases with wealth and decreases with probability of surviving the current period. It may also depend (implicitly) on factors including life expectancy, age, anticipated future health and income, and numerous other factors that can affect the difference in utility between surviving the current period or not, and the expected opportunity cost of spending on risk reduction.

When extrapolating estimates of VSL from populations in high-income countries (to which most high-quality estimates pertain) to populations in lower-income and middle-income countries, one must in principle account for differences in many of the factors that can influence VSL. The factors discussed here are summarized in Table 2. Smaller wealth, income, and consumption in target populations should decrease VSL. The standard model provides little guidance on the magnitude of this effect and differences in the structure of income and consumption (including market and nonmarket, government and nongovernment components) raise questions about what measure of income is most appropriate for extrapolation. Smaller annual survival probabilities should increase VSL, though often to a negligible extent. Effects of life expectancy, age, and other factors can also influence the extrapolation and the most appropriate resolutions of these issues are unknown. 
Table 2 Summary of predicted effects (LMIC compared with US or other high-income country).

\begin{tabular}{lll}
\hline Factor & Direction & Magnitude \\
\hline Income or wealth & Smaller & $\begin{array}{l}\text { Wealth elasticity } \geqslant \text { coefficient of relative risk aversion } \\
\text { with respect to wealth (poorly estimated, perhaps 0.5 to } \\
2.5 \text { or more). }\end{array}$ \\
$\begin{array}{l}\text { Age-specific current } \\
\text { mortality risk }\end{array}$ & Larger & $\begin{array}{l}\text { Proportional effect smaller than reciprocal of } \\
\text { period-specific survival probability in LMIC, often } \\
\text { negligible. }\end{array}$ \\
$\begin{array}{l}\text { Age } \\
\text { Ambiguous }\end{array}$ & $\begin{array}{l}\text { In some models, VSL increases then decreases with age; } \\
\text { relationship between patterns in populations with } \\
\text { different life expectancies is unknown. }\end{array}$ \\
$\begin{array}{l}\text { Anticipated health, access } \\
\text { to health care }\end{array}$ & Ambiguous & \\
$\begin{array}{l}\text { Formal and informal } \\
\text { support networks } \\
\begin{array}{l}\text { Cultural, religious, other } \\
\text { factors }\end{array}\end{array}$ & Unknown & \\
\hline
\end{tabular}

Acknowledgments: The author thanks the editors and reviewers for their helpful comments.

\section{References}

Aldy, Joseph E. \& Viscusi, W. Kip (2008). Adjusting the Value of a Statistical Life for Age and Cohort Effects. Review of Economics and Statistics, 90, 573-581.

Bergstrom, Ted (1982). When is a Man's Life Worth More Than His Human Capital? In W. Jones-Lee Michael (Ed.), The Value of Life and Safety. Amsterdam: North-Holland Publishing Co.

Breyer, Friedrich \& Stefan, Felder (2005). Mortality Risk and the Value of a Statistical Life: The Dead-Anyway Effect Revis(it)ed. Geneva Risk and Insurance Review, 30, 41-55.

Bucks, Brian K., Kennickell, Arthur B. \& Moore, Kevin B. (2006). Recent Changes in U.S. Family Finances: Evidence from the 2001 and 2004 Survey of Consumer Finances. Federal Reserve Bulletin, 92, A1-A38.

Drèze, Jacques (1962). L'Utilité Sociale d'une Vie Humaine. Revue Française de Recherche Opérationnelle, 6, 93-118.

Eeckhoudt, Louis R. \& Hammitt, James K. (2001). Background Risks and the Value of a Statistical Life. Journal of Risk and Uncertainty, 23, 261-279.

Finkelstein, Amy, Luttmer, Erzo F. P. \& Notowidigdo, Matthew J. (2013). What Good is Wealth without Health? The Effect of Health on the Marginal Utility of Consumption. Journal of the European Economic Association, 11(S1), 221-258. 
Gerking, Shelby \& Dickie, Mark (2013). Valuing Reductions in Environmental Risks to Children's Health. Annual Review of Resource Economics, 5, 245-260.

Grosse, Scott D. (2003). Appendix I: Productivity Loss Tables. In Anne C. Haddix, Steven M. Teutsch \& Phaedra S. Corso (Eds.), Prevention Effectiveness: A Guide to Decision Analysis and Economic Evaluation. New York: Oxford University Press.

Hammitt, James K. \& Robinson, Lisa A. (2011). The Income Elasticity of the Value per Statistical Life: Transferring Estimates between High and Low Income Populations. Journal of Benefit-Cost Analysis, 2(1), Article 1.

Hoffmann, Sandra, Krupnick, Alan \& Qin, Ping (2017). Building a Set of Internationally Comparable VSL Studies: Estimates of Chinese Willingness to Pay to Reduce Mortality Risk. Journal of Benefit-Cost Analysis, 8(2), 251-289.

Jones-Lee, Michael W. (1974). The Value of Changes in the Probability of Death or Injury. Journal of Political Economy, 82, 835-849.

Kaplow, Louis (2005). The Value of a Statistical Life and the Coefficient of Relative Risk Aversion. Journal of Risk and Uncertainty, 31, 23-34.

Krupnick, Alan (2007). Mortality-risk Valuation and Age: Stated Preference Evidence. Review of Environmental Economics and Policy, 1, 261-282.

Ng, Yew-Kwang (1992). The Older the More Valuable: Divergence Between Utility and Dollar Values of Life as One Ages. Journal of Economics, 55, 1-16.

Pratt, John W. (1964). Risk Aversion in the Small and in the Large. Econometrica, 32, 122-136.

Pratt, John W. \& Zeckhauser, Richard J. (1996). Willingness to Pay and the Distribution of Risk and Wealth. Journal of Political Economy, 104, 747-763.

Rosen, Sherwin (1988). The Value of Changes in Life Expectancy. Journal of Risk and Uncertainty, 1, 285-304.

Shepard, Donald S. \& Zeckhauser, Richard J. (1984). Survival versus Consumption. Management Science, 30, 423-439.

Sloan, Frank A., Viscusi, W. Kip, Chesson, Harrell W., Conover, Christopher J. \& WhettenGoldstein, Kathryn (1998). Alternative Approaches to Valuing Intangible Health Losses: The Evidence for Multiple Sclerosis. Journal of Health Economics, 17, 475-497.

Viscusi, W. Kip (2004). The Value of Life: Estimates with Risks by Occupation and Industry. Economic Inquiry, 42, 29-48.

Viscusi, W. Kip \& Evans, William N. (1990). Utility Functions that Depend on Health Status: Estimates and Economic Implications. American Economic Review, 81, 353-374.

Viscusi, W. Kip \& Masterman, Clayton (2017). Income Elasticity and the Global Value of a Statistical Life. Journal of Benefit-Cost Analysis, 8(2), 226-250.

Weinstein, Milton C., Shepard, Donald S. \& Pliskin, Joseph S. (1980). The Economic Value of Changing Mortality Probabilities. Quarterly Journal of Economics, 94, 373-396.

World Bank (2008). Global Purchasing Power Parities and Real Expenditures. Washington DC. 